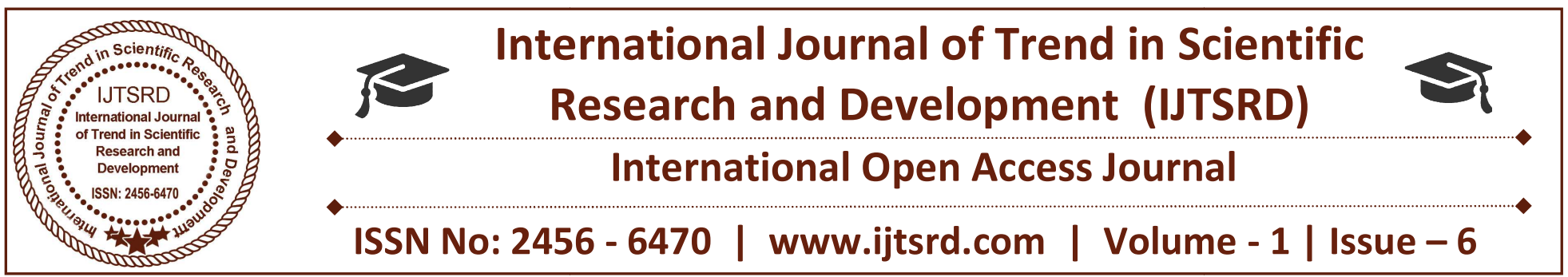

\title{
A Paradigm Shift in Self Care Management of Diabetes Mellitus - A Review
}

\author{
Manjula GB \\ Professor, College of Nursing Sciences, \\ Dayananda Sagar University, Bangalore
}

\begin{abstract}
Diabetes is a complex illness that affects all aspects of a person's life. Each person makes many diabetes related choices each day. Education is regarded as an essential part in diabetes care to enable people with diabetes self-care. Medical model often fails to adequately account for the person, his/her social context or the role of the health care provider. This model was often not well taken by patients. A new approach was needed that recognized that patients are in control of and responsible for the daily selfmanagement of diabetes and that, to succeed, a selfmanagement plan had to fit patients' goals, priorities, and lifestyle as well as their diabetes. In empowerment approach, patients are seen as experts on their own lives and the professional is seen as expert on diabetes who serves as a resource person. The role of educator is to help patients to achieve skills and to overcome barriers through education, self exploration and emotional support. The empowerment philosophy involves establishing partnerships with individual patients and creating truly patient-centered practices. The benefits for patients include better communication with providers, greater satisfaction with care, improved metabolic and psychosocial outcomes, emotional wellbeing and quality of life.
\end{abstract}

Keywords: Traditional model, empowerment model, self care, diabetes mellitus

\section{Introduction}

It has been estimated that the global burden of type 2 diabetes mellitus (T2DM) for 2010 would be 285 million people which is projected to increase to 438 million in 2030. Total number of people with diabetes in India will rise to 87 million by 2030 (IDF). A gap currently exists between the promise and the reality of diabetes care. Diabetes is a complex illness that affects all aspects of a person's life. Each person makes many diabetes related choices each day. Education is regarded as an essential part in diabetes care to enable people with diabetes self-care. The purpose of education is to provide a combination of knowledge, skills and heightened self awareness regarding values, needs and goals so that patients can use this power to act in their own self interest. Together these ideas began to shape a philosophy that is described as empowerment. Patients are empowered when they have knowledge, skills, attitudes and self awareness necessary to influence their own behavior and that of others in order to improve the quality of their lives. The World Bank has defined empowerment as "the process of increasing capacity of individuals or groups to make choices and to transform those choices into desired actions and outcomes" 1

\section{Need of Empowering People with Diabetes}

The compelling evidence that modest lifestyle changes can prevent type 2 diabetes is an enormous shot in the arm for chronic disease prevention and health promotion. Nevertheless, translating these findings into effective intervention programmes both at clinical and public health levels may be challenging. Diabetes is a chronic illness. The biggest challenge in a chronic illness is that patients not only have to accept their disease condition but also have to live with it and adapt to it. In diabetes management, patients are required to take up an equal share of 
responsibility in treatment along with their health care team.

The English diabetes service framework standards document refers to empowering people with diabetes to 'enhance their personal control over the day-to-day management of their diabetes in a way that enables them to experience the best possible quality of life'. This is achieved by the provision of information, education and psychological support. It also goes on to reaffirm that 'people with diabetes need the knowledge, skills and motivation to assess their risks, to understand what they will gain from changing their behaviour or lifestyle and to act on that understanding by engaging in appropriate behaviours. Patient education, information and involvement are also priorities set out in the other national diabetes frameworks and health plans.

Self care is possible only by empowering people with necessary knowledge, skills and problem solving ability to adequately deal with the disease so that much better glycemic control and quality of life is possible.

In the past, medical model promoted the idea that health professionals know best, and great effort was made to encourage patients to follow the recommendations of health professionals. This approach was based on the belief that patients have an obligation to follow the direction of their providers and that the benefits of compliance outweigh the impact of these recommendations on patients' quality of life. The traditional medical model represents medical disease as pathology model in which the professional is viewed as the powerful expert provider and the patient as a passive recipient. Medical model often fails to adequately account for the person, his/her social context or the role of the health care provider. Dissatisfaction with this model lead to a rise in consumerism among patients with chronic illness. Consumer model does provide patients with the ability to become more active participants in their care; however, when patients feel the entire burden of responsibility for their health care, they often feel dissatisfied. As the large literature in noncompliance indicates, these models were not effective in diabetes care. $^{2,3}$. A new approach was needed that recognized that patients are in control of and responsible for the daily self-management of diabetes and that, to succeed, a self-management plan had to fit patients' goals, priorities, and lifestyle as well as their diabetes. In empowerment approach, patients are seen as experts on their own lives and the professional is seen as expert on diabetes who serves as a resource person. The role of educator is to help patients to achieve skills and to overcome barriers through education, self exploration and emotional support. This approach is based on three fundamental aspects of chronic illness care: choices, control, and consequences. ${ }^{4}$

The choices that patients make each day as they care for diabetes have a greater impact on their outcomes than those made by health professionals. In addition, patients are in charge of their self-management behaviors. Finally, because the consequences for these decisions accrue directly to patients, they have both the right and the responsibility to manage diabetes in the way that is best suited to the context and culture of their lives.

Table 1: Comparison of Traditional Medical Model \& Empowerment Model

\begin{tabular}{|c|l|l|}
\hline $\begin{array}{c}\text { SL } \\
\text { NO }\end{array}$ & TRADITIONAL MEDICAL MODEL & \multicolumn{1}{|c|}{ EMPOWERING PATIENT CENTERED } \\
MODEL
\end{tabular}




\begin{tabular}{|l|l|l|l|}
\hline 5 & $\begin{array}{l}\text { Goal is compliance with } \\
\text { recommendations. Behavioural strategies } \\
\text { are used to increase compliance with } \\
\text { recommended treatment A lack of } \\
\text { compliance is viewed as a failure of } \\
\text { patients and provider. }\end{array}$ & $\begin{array}{l}\text { Goal is to enable patients to make informed } \\
\text { choices. Behavioural strategies are used to help } \\
\text { patients change behavior of their choosing. A lack } \\
\text { of goal achievement is viewed as feedback and } \\
\text { used to modify goals and strategies. }\end{array}$ \\
\hline $\mathbf{6}$ & $\begin{array}{l}\text { Behaviour changes are externally } \\
\text { motivated }\end{array}$ & $\begin{array}{l}\text { Behaviour changes are internally motivated } \\
\text { patient is powerless, professional is }\end{array}$ & Patient and professional are powerful \\
\hline $\mathbf{7}$ & \begin{tabular}{l} 
powerful \\
\hline
\end{tabular}
\end{tabular}

Patient education designed to empower patients to deal with diabetes in a biopsychosocial context has a very different goal than diabetes patients' education that is designed to persuade patients to comply with treatment recommendations of health professionals in order to improve their physical status.

\section{Empowerment model of behaviour change}

Several studies have shown that inspite of having adequate knowledge and attitude towards management of diabetes, it seldom brings about a change in practice. ${ }^{5,6}$

This reflects a need of helping patients discover and develop their inherent capacity to be responsible for their own lives and gain mastery over their diabetes.

Research has documented that the patient empowerment approach is effective in the diabetes care. 7 Studies have also examined that incorporating empowerment principles in diabetes self management interventions may be useful for supporting patients' self-management efforts ${ }^{8}$

In diabetes disease management, the importance of patient empowerment has been recognized and the paradigm is shifting from a traditional providercentered model to a patient-centered model. Although good practices of physicians and other health care providers are important, disease management is not solely in the hands of health care providers. Moreover, many psychological, emotional, social, spiritual, cognitive, economic, literacy, and cultural factors are intertwined with diabetes management, and traditional medical models usually ignore these important factors.

\section{How to empower patients with diabetes mellitus}

Within the empowerment model, the role of the health care providers is "to inspire, inform, support and facilitate their patients to identify and attain their own goals". Instead of applying behavior strategies to patients to change behavior, the health care providers should explain these strategies to their patients and allow them to make changes in behaviors of their own choosing. Because these changes are identified by the patients as being important to them, they are more likely to maintain the changes. In a review article on the empowerment approach, the literature revealed that there are five key features to an empowering consultation: acceptance, affect, autonomy, alliance and active participation ${ }^{9}$

Acceptance refers to the respect by health care professional for the diabetic Patient regardless of the degree of the metabolic control, lifestyle, appearance or attitude of the patient. Affect refers to the emotional aspect of the empowering consultation. Exploring the emotional aspects and barriers enhance the patient's motivation to address the problem and methods of behavioral change. Autonomy relates to the involvement and participation of the patient in the decision making during consultation. Active participation means that the patient should be the main decision maker. The role of the health personnel is to actively guide the patient.

Based on review of literature, patients with diabetes can be empowered by following the steps mentioned below.

Assessment: Assessment includes all aspects of diabetes as a biopsychosocial illness ie. Physical, emotional, cognitive, knowledge, behavior skills and awareness necessary for self care. Assessment also includes review of diabetes skills ( self monitoring, injections, hypoglycemic 
management, food identification), biomedical measures( changes in body weight, glycated hemoglobin), evidence of appropriated behavior ( footcare) Educator also reviews patients actual self care practices and recommended self care practices.

> Imparting knowledge: Patient experiences can be used as the curriculum and design a group educational programme and ensure that the content provided is relevant for the needs of the group. Interactive teaching strategies are required involving patients in problem solving and addressing their cultural and psychosocial needs. Various treatment options, cost and benefits for each option are reviewed.

$>$ Emphasizing patient's responsibility for self care: Helps patient clarify personal values specific to diabetes, helps patient assess level of personal responsibility for diabetes care and helps patient select diabetes care goals. Patients who participate in the selection of goals have clarity about them and are more likely to be successful in achieving goals.

$>$ Identification of strength and barriers: Patient identifies beliefs, thoughts and feelings that may act as barriers and identifies strengths related to achieving self care.

$>$ Assuming responsibility: Patient develops skills to optimize support, identifies potential barriers and learns strategies/ skills to overcome barriers.

> Commitment towards action: Patient identifies long-term goals and establishes plan with assistance from provider towards which patient will work. Patient commit to making a behavior change and carries out the plan that will help them to achieve their long term goals.

Evaluation: Patient and provider evaluate and review plan using problem solving model.

\section{CONCLUSION}

Diabetes is a complex disease and each patient makes diabetes related choices every day. Patients need to be empowered by providing knowledge, skills and heightened self awareness so that they can act on their own self interest.

The empowerment philosophy involves establishing partnerships with individual patients and creating truly patient-centered practices. The benefits for patients include better communication with providers, greater satisfaction with care, improved metabolic and psychosocial outcomes, emotional wellbeing and quality of life. The benefits for providers include achievement of recommended standards of care, improved outcomes, and greater professional satisfaction.

It can be concluded that empowerment is not a technique or a strategy, but a view of how care is provided. Successful empowering interventions cannot be fully shared or "standardized" across multiple populations, but must be created within or adapted to local contexts.

\section{BIBLIOGRAPHY}

1) What is empowerment? The World Bank, 2005, (http://web.worldbank.org/WBSITE/EXTERNAL/ TOPICS/EXTPOVERTY/EXTEMPOWE RMENT/0, content accessed 17 August 2011).

2) Funnell MM, Anderson RM: The problem with compliance in diabetes. JAMA284:1709, 2000

3) 3.Anderson RM, Funnell MM: Compliance and adherence are dysfunctional concepts in diabetes care. Diabetes Educ 26:597 -604, 2000

4) Rubin RR, Anderson RM, Funnell MM: Collaborative diabetes care. Pract

Diabetol 21:29 -32, 2002

5) Subish P, Leelavthy DA, et al. Impact of counseling hospitalized diabetic patients. Journal of Pharmacy Practice and Research Vol.36, No.1, 2006

6) Anderson R.M., Funnell M.M. Aikens J. E. Evaluating the Efficacy of an EmpowermentBased Self-Management Consultant Intervention: Results of a Two-Year Randomized Controlled Trial. Ther Patient Educ. 2009 June 1; 1(1): 3-11.

7) Anderson RM, Funnell MM, Butler PM, et al. Patient empowerment. Results of a randomized controlled trial. Diabetes Care. 1995 Jul;18(7):943-9.

8) Tang TS, Funnell MM, Brown MB, Kurlander JE. Self-management support in "real-world" settings: an empowerment-based intervention. Patient Educ Couns. 2010 May;79(2):178-84

9) Skinner TC, Cradock S. Empowerment: what about the evidence? Practical Diabetes International 2000;17:91-5. 